\title{
Preoperative intramuscular adipose tissue content is a novel prognostic predictor after hepatectomy for hepatocellular carcinoma.
}

\section{$\operatorname{AUTHOR}(\mathrm{S}):$}

Hamaguchi, Yuhei; Kaido, Toshimi; Okumura, Shinya; Ito, Takashi; Fujimoto, Yasuhiro; Ogawa, Kohei; Mori, Akira; Hammad, Ahmed; Hatano, Etsuro; Uemoto, Shinji

\section{CITATION:}

Hamaguchi, Yuhei ...[et al]. Preoperative intramuscular adipose tissue content is a novel prognostic predictor after hepatectomy for hepatocellular carcinoma.. Journal of hepatobiliary-pancreatic sciences 2015, 22(6): 475-485

\section{ISSUE DATE:}

2015-03-05

\section{URL:}

http://hdl.handle.net/2433/201493

\section{RIGHT:}

This is the peer reviewed version of the following article: Hamaguchi, Y, Kaido, T, Okumura, S, Ito, T, Fujimoto, Y, Ogawa, K, Mori, A, Hammad, A, Hatano, E, and Uemoto, S (2015), Preoperative intramuscular adipose tissue content is a novel prognostic predictor after hepatectomy for hepatocellular carcinoma. J Hepatobiliary Pancreat Sci, 22, 475-485, which has been published in final form at http://dx.doi.org/10.1002/jhbp.236. This article may be used for non-commercial purposes in accordance with Wiley Terms and Conditions for Self-Archiving.; The full-text file will be made open to the public on 5 March 2016 in accordance with publisher's 'Terms and Conditions for Self-Archiving'.; この論文は出版社版 でありません。引用の際には出版社版をご確認ご利用ください。; This is not the published version. Please cite only the published version. 


\section{Title Page}

Preoperative intramuscular adipose tissue content (IMAC) is a novel prognostic predictor after hepatectomy for hepatocellular carcinoma

Yuhei Hamaguchi, Toshimi Kaido, Shinya Okumura, Takashi Ito, Yasuhiro Fujimoto, Kohei

Ogawa, Akira Mori, Ahmed Hammad, Etsuro Hatano, Shinji Uemoto

Division of Hepato-Biliary-Pancreatic and Transplant Surgery, Department of Surgery,

Graduate School of Medicine, Kyoto University, 54 Kawahara-cho, Shogoin, Sakyo-ku,

Kyoto 606-8507, Japan

\section{Corresponding author:}

Toshimi Kaido, MD, PhD

Address: Division of Hepato-Biliary-Pancreatic and Transplant Surgery, Department of

Surgery, Graduate School of Medicine, Kyoto University, 54 Kawahara-cho, Shogoin,

Sakyo-ku, Kyoto 606-8507, Japan.

Phone: $+81-75-751-3242 \quad$ Fax: $+81-75-751-4263$

E-mail: kaido@kuhp.kyoto-u.ac.jp 
Key words: hepatocellular carcinoma, intramuscular adipose tissue content, prognostic factor, sarcopenia

Word count of Abstract: 197

Word count of manuscript (including references): 3766

Tables count: 3

Figures count: 2 


\begin{abstract}
Background Sarcopenia has been shown to be an independent predictor of lower

disease-free and overall survival in various kinds of diseases. The quality of skeletal muscle has recently attracted much attention as a new parameter of sarcopenia.
\end{abstract}

Methods We performed a retrospective analysis of 477 patients undergoing hepatectomy for HCC between April 2005 and August 2014. The quality of skeletal muscle was evaluated by intramuscular adipose tissue content (IMAC) using preoperative CT imaging. The impact of IMAC on outcomes after hepatectomy for HCC was analyzed.

Results Patients with high IMAC showed older age, higher body mass index, higher indocyanine green retention test at $15 \mathrm{~min}$, and more operative blood loss. The overall and recurrence-free survival rates were significantly lower in patients with high IMAC than in patients with normal IMAC $(P<0.0001, P=0.0012$, respectively $)$. Multivariate analysis showed that high IMAC was the significant risk factor for death (hazard ratio $[\mathrm{HR}]=2.942 ; P$ $<0.0001)$ and for HCC recurrence $(\mathrm{HR}=1.529 ; P=0.0007)$ after hepatectomy.

Conclusions Preoperative quality of skeletal muscle was closely correlated with postoperative mortality and HCC recurrence. IMAC could be incorporated into new selection criteria for hepatectomy for HCC. 


\section{Introduction}

Sarcopenia is defined as a syndrome characterized by progressive and generalized loss of skeletal muscle mass and strength [1]. The prognostic significance of sarcopenia has been reported in various kinds of diseases including cancer [2-4]. Most previous studies have investigated only skeletal muscle mass to define sarcopenia because muscle strength and function are difficult to evaluate, though The European Working Group on Sarcopenia in Older People has recommended that the definition of sarcopenia should include not only low muscle mass, but also low muscle strength or function [1]. Recently, it has been reported that the increase in intramuscular adipose tissue (IMAT) with aging was associated with muscle weakness and poor function, one of the components of sarcopenia [5]. Kitajima et al [6]. showed that the quality of skeletal muscle could be evaluated by measuring intramuscular adipose tissue content (IMAC), and that IMAC was linked to the severity of non-alcoholic steatohepatitis (NASH). In our previous study, preoperative lower quality of skeletal muscle evaluated by IMAC was an independent and significant risk factor for poor survival in patients undergoing living donor liver transplantation [7]. Thus, the quality of skeletal muscle has recently attracted much attention as a new parameter of sarcopenia.

Hepatocellular carcinoma (HCC) is one of the most common human cancers, and its incidence is still increasing worldwide $[8,9]$. HCC is a highly malignant tumor characterized by rapid progression, frequent tumor recurrence, and metastasis. To date, there has been no 
successful systemic chemotherapy for patients with advanced HCC, and surgical treatment, including hepatectomy and liver transplantation, is the most effective modality for the treatment for HCC [9]. While advances in preoperative diagnosis, surgical technique, and perioperative management have improved overall and recurrence-free survival after partial hepatectomy for $\mathrm{HCC}$, even in patients with curative resection, the postoperative recurrence rate remains high, with a five-year recurrence rate of up to $70 \%$ [10].

Recent study has shown that sarcopenia defined as lower skeletal muscle mass was an independent prognostic factor for mortality after hepatectomy for HCC [11, 12]. However, measuring only the area of skeletal muscle using CT imaging may not be sufficient to evaluate lean muscle mass because we could not distinguish muscle from adipose tissue with that method, which might mislead us to evaluate low lean muscle mass with much adipose tissue as normal skeletal muscle mass.

In the present study, we evaluated the quality of skeletal muscle by measuring IMAC as a new parameter of sarcopenia, and investigated the impact of sarcopenia on outcomes in patients undergoing hepatectomy for HCC.

\section{Patients and methods}

\section{Patients}

There were 547 patients who underwent hepatectomy for HCC at Kyoto University Hospital 
between April 2005 and August 2014. Seventy patients who did not have preoperative plain computed tomography (CT) imaging at the umbilical level were excluded from this study. Therefore, a total of 477 patients (389 men, 88 women) were enrolled in the present study. The study was approved by the Ethics Committee of Kyoto University and conducted in accordance with the Declaration of Helsinki of 1996.

Hepatic resection was usually performed using the Cavitron Ultrasonic Surgical Aspirator (CUSA) and a bipolar cautery device equipped with a channel for water dripping, with an intermittent Pringle maneuver, or selective vascular clamping if necessary. A pathological examination was performed to evaluate tumor size, tumor number, vascular invasion, tumor differentiation, and background liver in accordance with the rules of the Liver cancer Study Group of Japan.

All patients were followed up every three months after operation with evaluation of tumor markers and CT or magnetic resonance imaging.

Imaging analysis

All CT imaging was obtained with a multidetector computed tomography scanner (Aquilion 64, Toshiba Medical Systems, Tochigi, Japan). The technical parameters used for CT were as follows: $120 \mathrm{kV}$ (tube voltage), $0.5 \mathrm{~mm} \times 64 \mathrm{row}$ (detector configuration), tube current modulation, $0.5 \mathrm{sec} /$ rotation (gantry rotation), and $7 \mathrm{~mm}$ reconstruction thickness. 
The quality of skeletal muscle was evaluated by IMAC. IMAC was calculated as previously described:

$\mathrm{IMAC}=$ region of interest $(\mathrm{ROI})$ of the multifidus muscle (Hounsfield units)/ROI of subcutaneous fat (Hounsfield units) [6, 7].

Subfascial muscular tissue in the multifidus muscle on the preoperative plain CT cross-sectional image at the umbilical level was precisely traced, and CT values (in Hounsfield units) were measured using the AquariusNET server (TeraRecon, Inc., San Mateo, CA, USA) (Fig. 1a). CT values were measured for ROIs of four circles on subcutaneous fat away from major vessels (Fig. 1b). The mean values of those four ROIs were used as the ROI of subcutaneous fat. In general, IMAC was shown with a negative value. Skeletal muscle with more IMAT shows higher IMAC, so higher IMAC means lower quality of skeletal muscle.

The quantity of skeletal muscle was evaluated by psoas muscle mass index (PMI). The cross-sectional areas of the bilateral psoas muscles were measured by manual tracing using preoperative CT images at the same level (Fig. 1c). The psoas muscle mass index (PMI) was calculated by normalizing the cross-sectional areas for height $\left(\mathrm{cm}^{2} / \mathrm{m}^{2}\right)$.

Receiver operating characteristic (ROC) curves were calculated in order to select the optimal cut-off values of IMAC and PMI for men and women separately. The cut-off values were selected on the basis of best accuracy in relation to an outcome (death). The cut-off values of IMAC in males and females were -0.324 (area under the curve $[\mathrm{AUC}]=0.687$ ) and -0.138 
$(\mathrm{AUC}=0.651)$, respectively. The cut-off values of PMI were $6.089(\mathrm{AUC}=0.548)$ and 4.020 $(\mathrm{AUC}=0.523) \mathrm{cm}^{2} / \mathrm{m}^{2}$, respectively

Analyzed parameters

The overall and recurrence-free survival rates after hepatectomy were investigated in patients classified according to IMAC or PMI. The prognostic factors were analyzed on the basis of the following variables: patient age, sex, etiology of $\mathrm{HCC}$, the presence of treatment history for HCC before hepatectomy, platelet count, indocyanine green retention test at $15 \mathrm{~min}$ (ICG R15), Child-Pugh classification, serum $\alpha$-fetoprotein (AFP) level, des- $\gamma$-carboxyprothrombin (DCP) level, liver histology, tumor size, number of tumors, microvascular invasion (MVI), tumor differentiation, pathological stage according to the Liver Cancer Study Group of Japan, surgical procedure, duration of surgery, estimated operative blood loss, body mass index (BMI), preoperative IMAC, and preoperative PMI.

Statistical analysis

Continuous variables were nonparametrically analyzed using the Mann-Whitney U test.

Categorical variables were compared using the $\chi^{2}$ test or Fisher's exact test where appropriate.

Correlation between continuous variables was assessed using Pearson correlation coefficients and linear regression. Cumulative overall and recurrence-free survival rates were calculated 
using Kaplan-Meier methods, and differences between curves were evaluated using the log-rank test. Any variable identified as significant $(P<0.05)$ or with $P<0.10$ in univariate analysis was considered a candidate for a multivariate Cox regression analysis. A $P$ value $<$ 0.05 was considered significant. All statistical data were generated using JMP 11 (SAS Institute, Cary, NC, USA) and Prism 6 (GraphPad Software, Inc., La Jolla, CA, USA).

\section{Results}

Patient characteristics

The baseline characteristics and laboratory data of the 477 patients are shown in Table 1 . The median patient age was 68 years (range, 31-89 years). The Child-Pugh classifications were A and B for 437 (92\%) and 40 patients (8\%), respectively. Two hundreds and eighty-nine patients $(61 \%)$ underwent primary hepatectomy as the initial treatment for HCC, while 189 patients (39\%) had treatment history before hepatectomy such as TACE or RFA. The median tumor size was $3.5 \mathrm{~cm}$ (range, $0.2-25 \mathrm{~cm}$ ). Pathological stages according to the Liver Cancer Study Group of Japan were I, II , III, and IV for 82 (17\%), 181 (38\%), 142 (30\%), and 72 patients (15\%), respectively. Microvascular invasion was identified in 152 patients (32\%). A significant positive relationship was observed between IMAC and patient age in both males $(\mathrm{r}=0.368, P<0.0001)$ and females $(\mathrm{r}=0.535, P<0.0001)$; therefore, the mean age in patients with high IMAC was significantly higher than in patients with normal $\operatorname{IMAC}(P<$ 
0.0001). Similarly, BMI in patients with high IMAC was significantly higher than in patients with normal BMI $(P=0.0002)$. The patients with normal IMAC showed more hepatitis B virus (HBV) or hepatitis $\mathrm{C}$ virus $(\mathrm{HCV})$-related $\mathrm{HCC}$ than those with high IMAC $(P=$ 0.0350). Among preoperative laboratory data, only ICG R15 was significantly higher in patients with high IMAC than in patients with normal IMAC $(P=0.0485)$. Tumor-associated factors were not significantly different between the two groups. Among operative factors, estimated blood loss in patients with high IMAC was significantly higher than in patients with normal IMAC $(P=0.0225)$.

Overall and recurrence-free survival rates after hepatectomy

The overall survival rate after hepatectomy for HCC was significantly lower in patients with high IMAC than in patients with normal IMAC $(P<0.0001$; Fig. 2a). In patients classified according to PMI, the overall survival rate was not significantly different between the two groups $(P=0.3178$; Fig. 2b). The recurrence-free survival rate was significantly lower in patients with high IMAC than in patients with normal IMAC $(P=0.0012$; Fig. $2 \mathrm{c})$. The recurrence-free survival rate in patients with low PMI was not significantly different from in patients with normal PMI $(P=0.7468$; Fig. 2 d $)$.

Risk factors for poor outcomes in patients undergoing hepatectomy 
The results of univariate and multivariate analysis of the overall survival in patients

undergoing hepatectomy for HCC are shown in Table 2. A multivariate Cox regression

analysis identified high serum AFP level ( $\geq 20 \mathrm{ng} / \mathrm{dl}$ ), advanced TNM stage, preoperative high

IMAC as independent risk factors for death after hepatectomy (Table 2).

Table 3 shows the results of univariate and multivariate analysis of the recurrence-free survival. Multivariate analysis showed that liver histology (liver fibrosis or liver cirrhosis), larger tumor size $(\geq 5.0 \mathrm{~cm})$, MVI, advanced TNM stage, and preoperative high IMAC were independent risk factors for HCC recurrence (Table 3).

\section{Discussion}

This retrospective study was the largest and first study to show that preoperative IMAC was the most significant prognostic factor for overall and recurrence-free survival in patients following hepatectomy for HCC. Recently, sarcopenia has attracted much attention as a prognostic factor for poor outcome in various kinds of diseases [2-4, 11, 12]. Although most recent studies have investigated only skeletal muscle mass to evaluate sarcopenia using CT imaging, measuring only the area of skeletal muscle using CT imaging may not be sufficient to evaluate lean muscle mass because we could not distinguish muscle from adipose tissue with that method. In other words, PMI does not always reflect actual muscle mass because the areas of psoas muscles measured in the present study include both muscle and IMAT. In some 
patients with a large amount of IMAT, their PMI could be calculated as normal even if their actual amount of muscle mass was low. Therefore, only measuring PMI could not detect such patients as having sarcopenia. On the other hand, high IMAC reflects not only more IMAT but also less muscle mass because IMAC is calculated as the ratio of CT values between skeletal muscle and subcutaneous fat tissue. In addition, a recent report from the Health, Aging and Body Composition (Health ABC) Study Cohort showed that the loss of strength was surprisingly much greater than the loss of muscle mass, which indicated that decline in muscle quality contributed to loss of strength [13]. It has been also shown that fat accumulation within skeletal muscle is associated with muscle weakness, poor function, and increased risk of incidental mobility limitations because it alters muscle fiber orientation and the force-producing capabilities of the whole muscle [14-16]. On the basis of these findings, we considered that IMAC could substitute for evaluation of muscle strength or function and could be the most appropriate parameter to evaluate preoperative sarcopenia instead of measuring only the cross-sectional areas of skeletal muscle.

The mechanisms by which sarcopenia produces an increased risk of mortality and morbidity are not fully understood. In the present study, patient age, BMI, preoperative ICG R15 and operative blood loss were significantly different between high IMAC group and normal IMAC group. Operative blood loss has been reported as independent prognostic factors for death or tumor recurrence after hepatectomy for HCC [17]. Among these parameters, only 
operative blood loss was shown to be a significant risk factor for death or HCC recurrence after hepatectomy as a result of univariate analysis, while it was not an independent risk factor. Recent evidence has shown that skeletal muscle loss with increasing adipose tissue leads to synthesize and secrete various kinds of pro-inflammatory adipokines such as leptin, TNF- $\alpha$, interleukin (IL)-1 and IL-6 [18]. Lutz et al. [19] showed that increase of such adipokines and decrease in adiponectin or IL-15 levels in aged or sarcopenic population had effects on the immune senescence, especially natural killer lymphocytes in innate immunity. Indeed, in the present study, we found more infectious postoperative complications in patients with high IMAC than in patients with normal IMAC $(22.0 \%$ vs $9.7 \% ; P=0.0002)$. This result is in line with previous study that showed the presence of sarcopenia increases the risk of sepsis-related death in cirrhotic patients, which might be due to impaired immunity [20]. Recently, with increased interest towards subsets of obesity-associated tumors, the role of adipose and muscle tissue interplay in carcinogenesis and cancer progression has attracted much attention $[21,22]$. It has been shown that among various kinds of adipokines, anti-inflammatory cytokines such as adiponectin presents anti-tumorigenic effects via various mechanisms [21]. On the other hands, pro-inflammatory adipokines such as leptin has been shown to promote growth and proliferation of tumor cells via activation various growth and survival signaling pathways [21]. In HCC, Sharma D et al. [23] reported that adiponectin has the molecular potential to inhibit the oncogenic actions of leptin by blocking Stat 3 and Akt phosphorylation. 
On the basis of these findings, we speculate that the increase in adiposity in sarcopenic patients could lead to imbalance between adipokines and myokines, which results in cancer growth and recurrence.

To improve sarcopenic status, beneficial effects can be obtained through exercise and amino acid supplementation using leucine-enriched mixture, by their regulation of mTOR signaling [24]. Today, BCAA nutrients, synbiotics and immune-modulating diet enriched with hydrolyzed whey peptide are used for all recipients as pre- and postoperative enteral nutrition in our institution. In our previous study, we found that perioperative nutritional therapy significantly improved posttransplant mortality in patients with low skeletal muscle mass measured by bioelectrical impedance analysis [25]. On the basis of these results, we are planning to prospectively evaluate the effect of preoperative nutritional therapy for improvement of IMAC, and investigate the impact of changes in IMAC on postoperative outcomes after hepatectomy for HCC.

The present study has several limitations. First, there was a possibility of selection bias for patient inclusion in the study group because as many cases were excluded from this study. We excluded 70 patients $(12.8 \%)$ for the sole reason of their having undergone no CT imaging at the umbilical level. This exclusion criterion was not related to the patients' general condition and severity of disease. Indeed, the mean values of preoperative blood examinations, the distribution of the Child-Pugh classification scores, etiology of HCC, operative factors, and 
tumor factors in this excluded population were almost similar to those of the study group.

Therefore, there was actually little selection bias for patient inclusion in the present study.

Second, we have to consider whether our cut-off values for IMAC and PMI were adequate to define sarcopenia. To date, several reports have each provided a definition of sarcopenia, but there is no criterion to define sarcopenia objectively [26, 27]. In the present study, we used ROC curves to determine the cut-off values of IMAC and PMI. The use of ROC curves is a more accurate and objective method than the use of SD for the design of cut-off values. We are now investigating IMAC and PMI considering age, sex, and BMI in healthy donors of liver transplantation; this investigation may determine more adequate cut-off values of IMAC and PMI to define sarcopenia.

In conclusion, the present study showed that the low quality of skeletal muscle evaluated by measuring IMAC was closely correlated with poor outcomes in patients undergoing hepatectomy for HCC. Preoperative IMAC could be incorporated into new selection criteria for hepatectomy for HCC.

Conflict of interest: None declared.

Author contributions: Study design: Hamaguchi, Kaido and Uemoto. Acquisition of data: Hamaguchi, Kaido, Okumura, Ito, Fujimoto, Ogawa, Mori, Hammad, Hatano. Analysis 
and interpretation: Hamaguchi and Kaido. Manuscript drafted by: Hamaguchi Revision:

Kaido and Uemoto 


\section{References}

1. Cruz-Jentoft AJ, Baeyens JP, Bauer JM, Boirie Y, Cederholm T, Landi F, et al. Sarcopenia: European consensus on definition and diagnosis: Report of the European Working Group on Sarcopenia in Older People. Age Ageing 2010; 39:412-23.

2. Prado CM, Lieffers JR, McCargar LJ, Reiman T, Sawyer MB, Martin L, et al. Prevalence and clinical implications of sarcopenic obesity in patients with solid tumours of the respiratory and gastrointestinal tracts: a population-based study. Lancet Oncol 2008; 9:629-35.

3. Tan BH, Birdsell LA, Martin L, Baracos VE, Fearon KC. Sarcopenia in an overweight or obese patient is an adverse prognostic factor in pancreatic cancer. Clin Cancer Res 2009; 15:6973-9.

4. van Vledder MG, Levolger S, Ayez N, Verhoef C, Tran TC, Ijzermans JN. Body composition and outcome in patients undergoing resection of colorectal liver metastases. Br J Surg 2012; 99:550-7.

5. Marcus RL, Addison O, Kidde JP, Dibble LE, Lastayo PC. Skeletal muscle fat infiltration: impact of age, inactivity, and exercise. J Nutr Health Aging 2010; 14:362-6.

6. Kitajima Y, Hyogo H, Sumida Y, Eguchi Y, Ono N, Kuwashiro T, et al. Severity of non-alcoholic steatohepatitis is associated with substitution of adipose tissue in skeletal muscle. J Gastroenterol Hepatol 2013; 28:1507-14. 
7. Hamaguchi Y, Kaido T, Okumura S, Fujimoto Y, Ogawa K, Mori A, et al. Impact of quality as well as quantity of skeletal muscle on outcomes after liver transplantation. Liver Transpl. Liver Transpl 2014; 20:1413-9.

8. Ferlay J, Shin HR, Bray F, Forman D, Mathers C, Parkin DM. Estimates of worldwide burden of cancer in 2008: GLOBOCAN 2008. Int J Cancer 2010; 127:2893-917.

9. Former A, Llovet JM, Bruix J. Hepatocellular carcinoma. Lancet 2012; 379:1245-55.

10. Llovet JM, Schwartz M, Mazzaferro V. Resection and liver transplantation for hepatocellular carcinoma. Semin Liver Dis 2005; 25:181-200.

11. Harimoto N, Shirabe K, Yamashita YI, Ikegami T, Yoshizumi T, Soejima Y, et al. Sarcopenia as a predictor of prognosis in patients following hepatectomy for hepatocellular carcinoma. Br J Surg 2013; 100:1523-30.

12. Voron T, Tselikas L, Pietrasz D, Pigneur F, Laurent A, Compagnon P, et al. Sarcopenia Impacts on Short- and Long-term Results of Hepatectomy for Hepatocellular Carcinoma. Ann Surg. In press.

13. Goodpaster BH, Park SW, Harris TB, Kritchevsky SB, Nevitt M, Schwartz AV, et al. The loss of skeletal muscle strength, mass, and quality in older adults: the health, aging and body composition study. J Gerontol A Biol Sci Med Sci 2006; 61:1059-64.

14. Delmonico MJ, Harris TB, Visser M, Park SW, Conroy MB, Velasquez-Mieyer P, et al. Longitudinal study of muscle strength, quality, and adipose tissue infiltration. Am J Clin 
Nutr 2009; 90:1579-85.

15. Goodpaster BH, Kelley DE, Thaete FL, He J, Ross R. Skeletal muscle attenuation determined by computed tomography is associated with skeletal muscle lipid content. $\mathbf{J}$ Appl Physiol (1985) 2000; 89:104-10.

16. Visser M, Kritchevsky SB, Goodpaster BH, Newman AB, Nevitt M, Stamm E, et al. Leg muscle mass and composition in relation to lower extremity performance in men and women aged 70 to 79: the health, aging and body composition study. J Am Geriatr Soc 2002; 50:897-904.

17. Katz SC, Shia J, Liau KH, Gonen M, Ruo L, Jarnagin WR, et al. Operative blood loss independently predicts recurrence and survival after resection of hepatocellular carcinoma. Ann Surg 2009; 249:617-23.

18. Tilg H, Moschen AR. Adipocytokines: mediators linking adipose tissue, inflammation and immunity. Nat Rev Immunol 2006; 6:772-83.

19. Lutz CT, Quinn LS. Sarcopenia, obesity, and natural killer cell immune senescence in aging: altered cytokine levels as a common mechanism. Aging (Albany NY) 2012; 4:53546.

20. Montano-Loza AJ, Meza-Junco J, Prado CM, Lieffers JR, Baracos VE, Bain VG, et al. Muscle wasting is associated with mortality in patients with cirrhosis. Clin Gastroenterol Hepatol 2012; 10:166-73. 
21. Dalamaga M. Interplay of adipokines and myokines in cancer pathophysiology: Emerging therapeutic implications. World J Exp Med 2013; 3:26-33.

22. Park J, Morley TS, Kim M, Clegg DJ, Scherer PE. Obesity and cancer--mechanisms underlying tumour progression and recurrence. Nat Rev Endocrinol 2014; 10:455-65.

23. Sharma D, Wang J, Fu PP, Sharma S, Nagalingam A, Mells J, et al. Adiponectin antagonizes the oncogenic actions of leptin in hepatocellular carcinogenesis. Hepatology 2010; 52: 1713-22.

24. Drummond MJ, Dreyer HC, Fry CS, Glynn EL, Rasmussen BB. Nutritional and contractile regulation of human skeletal muscle protein synthesis and mTORC1 signaling. J Appl Physiol (1985) 2009; 106:1374-84.

25. Kaido T, Ogawa K, Fujimoto Y, Ogura Y, Hata K, Ito T, et al. Impact of sarcopenia on survival in patients undergoing living donor liver transplantation. Am J Transplant 2013; $13: 1549-56$.

26. Jenssen I, Heymsfield SB, Ross R. Low relative skeletal muscle mass (sarcopenia) in older persons is associated with functional impairment and physical disability. J Am Geriatr Soc 2002; 50:889-96.

27. Chien MY, Huang TY, Wu YT. Prevalence of sarcopenia estimated using a bioelectrical impedance analysis prediction equation in community-dwelling elderly people in Taiwan. J Am Geriatr Soc 2008; 56:1710-5. 


\section{Figure legends}

Fig. 1 Cross-sectional computed tomographic images of (a) subfascial muscular tissue in the multifidus muscle, (b) subcutaneous fat (four small circles) and (c) bilateral psoas muscles at the umbilical level.

Fig. 2 (a) Overall survival rates after hepatectomy in patients classified according to IMAC.

The overall survival rate was significantly lower in patients with high IMAC than in patients with normal IMAC $(P<0.0001)$. (b) Overall survival rates after hepatectomy in patients classified according to PMI. The overall survival rate was not significantly different between the two groups $(P=0.3178)$. (c) Recurrence-free survival rates after hepatectomy in patients classified according to IMAC. The recurrence-free survival rate was significantly lower in patients with high IMAC than in patients with normal IMAC $(P=0.0012) .(\mathbf{d})$

Recurrence-free survival rates after hepatectomy in patients classified according to PMI. The recurrence-free survival rate in patients with low PMI was not significantly different from in patients with normal PMI $(P=0.7468)$. 
(a)

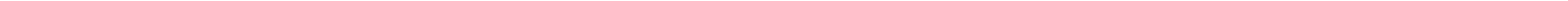

(b)

KURENAIIII

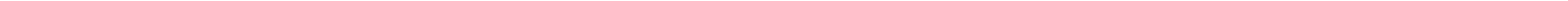

Fig. 1 


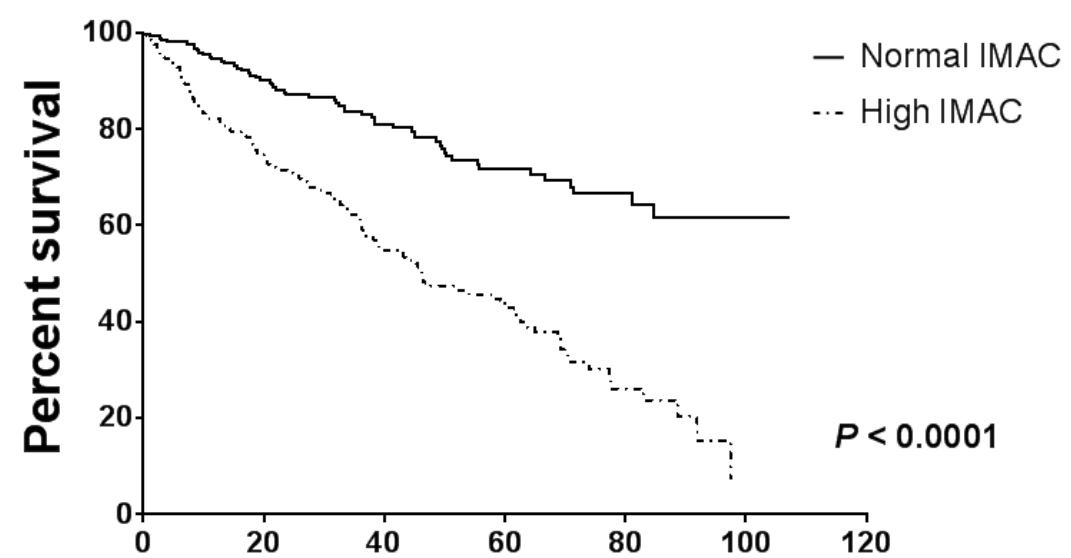

No. at risk

Months after hepatectomy

$\begin{array}{lllllll}\text { Normal } & 268 & 181 & 121 & 78 & 30 & 12 \\ \text { High } & 209 & 131 & 80 & 47 & 14 & 0\end{array}$

(c)

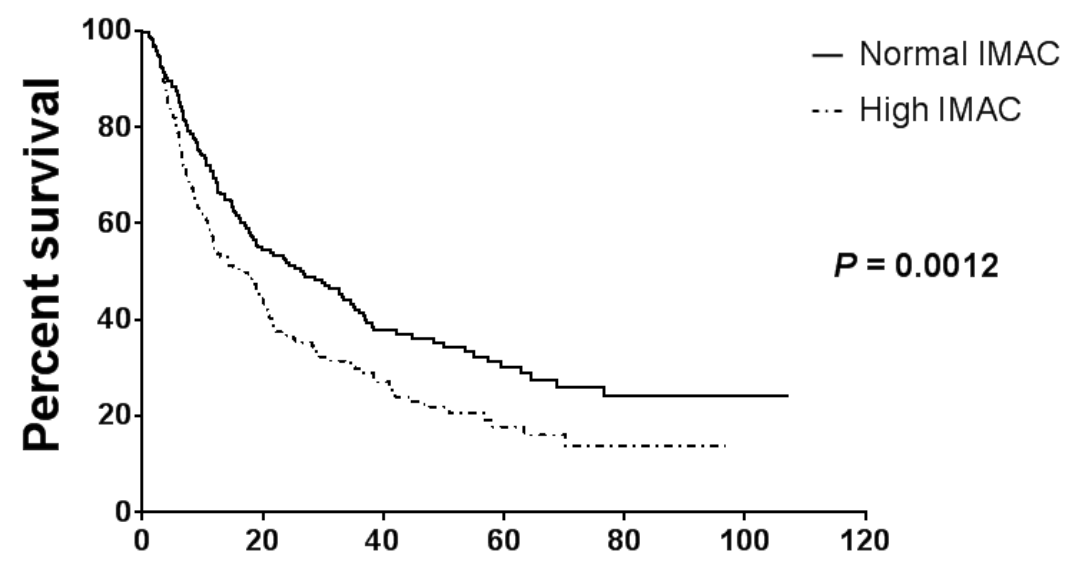

No. at risk

Months after hepatectomy

$\begin{array}{lllllll}\text { Normal } & 268 & 107 & 49 & 28 & 13 & 6\end{array}$

$\begin{array}{lllllll}\text { High } & 209 & 65 & 28 & 12 & 5 & 0\end{array}$

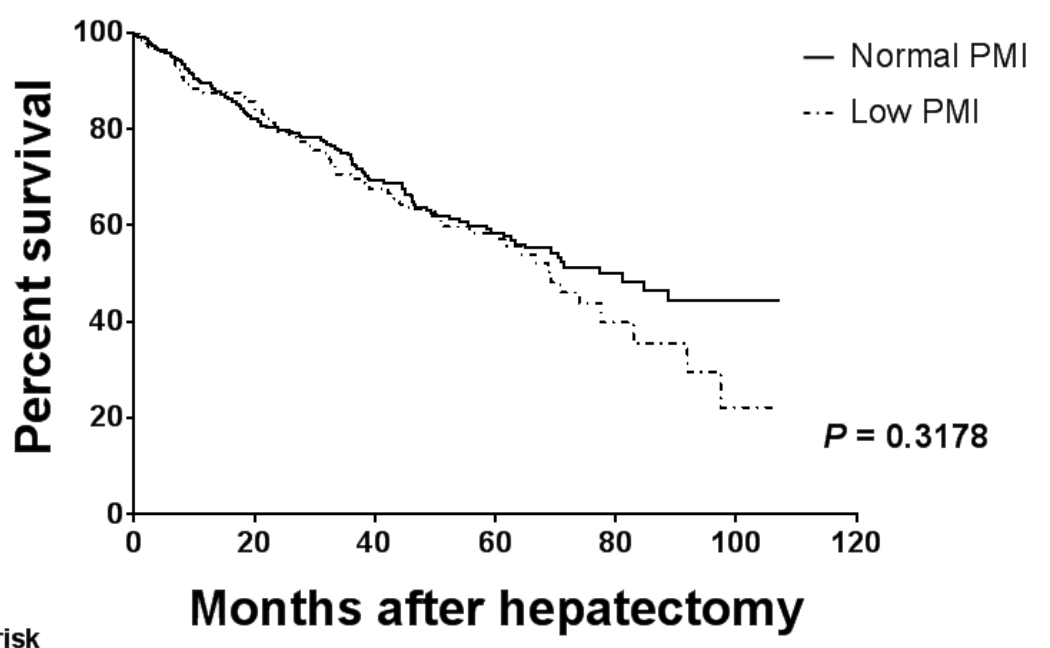

No. at risk

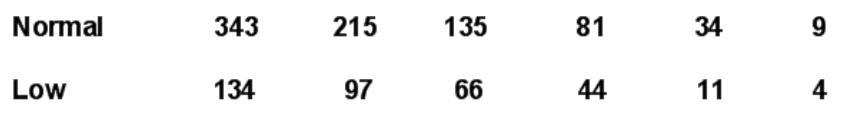

(d)

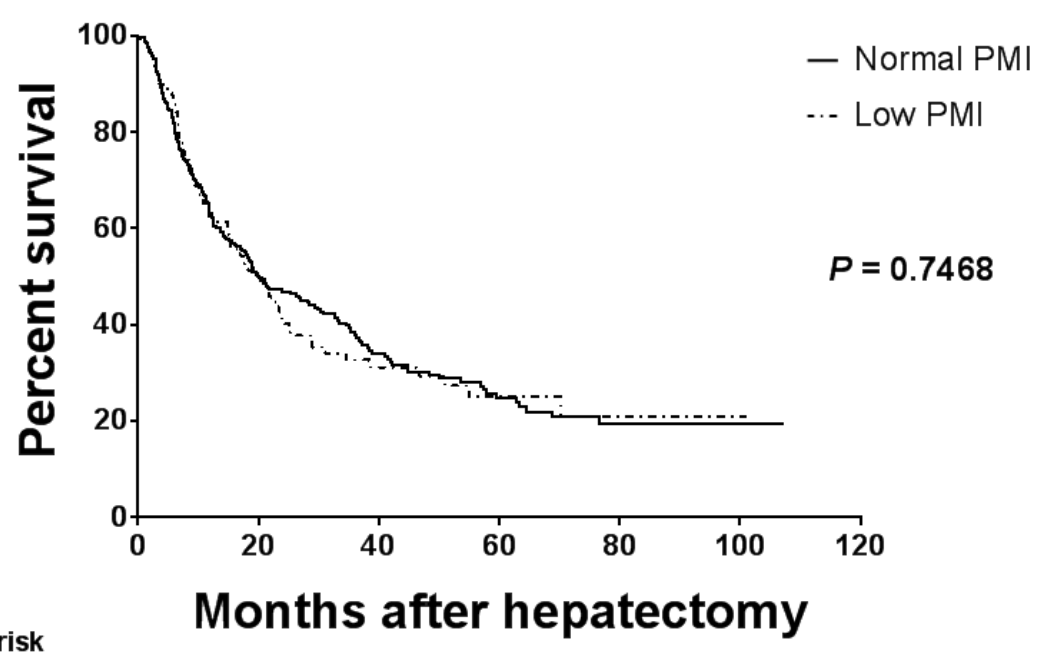

$\begin{array}{llllll}343 & 124 & 57 & 30 & 13 & 5\end{array}$

$\begin{array}{llllll}134 & 47 & 21 & 10 & 6 & 2\end{array}$

Fig. 2 
Table 1 Characteristics of patients classified according to IMAC

\begin{tabular}{|c|c|c|c|c|}
\hline Characteristic & $\begin{array}{c}\text { Total } \\
(\mathrm{n}=477)\end{array}$ & $\begin{array}{l}\text { High IMAC } \\
\quad(\mathrm{n}=209)\end{array}$ & $\begin{array}{l}\text { Normal IMAC } \\
\qquad(\mathrm{n}=268)\end{array}$ & $P$ \\
\hline \multicolumn{5}{|l|}{ Age (years) } \\
\hline Mean (SD) & $67(10)$ & $71(7)$ & $64(10)$ & $<0.0001$ \\
\hline \multicolumn{5}{|l|}{ Sex, n $(\%)$} \\
\hline Men & $389(82)$ & $171(82)$ & $218(81)$ & \multirow[t]{2}{*}{0.8944} \\
\hline Women & $88(18)$ & $38(18)$ & $50(19)$ & \\
\hline \multicolumn{5}{|l|}{$\mathrm{BMI}\left(\mathrm{kg} / \mathrm{m}^{2}\right)$} \\
\hline Mean (SD) & $23.1(3.4)$ & $23.9(3.6)$ & $22.6(3.1)$ & 0.0002 \\
\hline \multicolumn{5}{|l|}{ Preoperative IMAC } \\
\hline \multicolumn{5}{|l|}{ Males } \\
\hline Mean (SD) & $-0.339(0.126)$ & $-0.232(0.091)$ & $-0.422(0.077)$ & $<0.0001$ \\
\hline \multicolumn{5}{|l|}{ Females } \\
\hline Mean (SD) & $-0.172(0.170)$ & $-0.020(0.120)$ & $-0.288(0.092)$ & $<0.0001$ \\
\hline \multicolumn{5}{|l|}{ Preoperative PMI, n (\%) } \\
\hline Normal & $343(72)$ & $145(69)$ & $198(74)$ & \multirow[t]{2}{*}{0.2784} \\
\hline Low & $134(28)$ & $64(31)$ & $70(26)$ & \\
\hline \multicolumn{5}{|l|}{ Etiology, n (\%) } \\
\hline $\mathrm{HBV}$ or/and $\mathrm{HCV}$ & $319(67)$ & $129(62)$ & $190(71)$ & \multirow[t]{2}{*}{0.0350} \\
\hline Others & $158(33)$ & $80(38)$ & 78 (29) & \\
\hline \multicolumn{5}{|c|}{ The presence of previous treatment for $\mathrm{HCC}, \mathrm{n}(\%)$} \\
\hline Yes & $188(39)$ & $85(41)$ & $103(38)$ & \multirow[t]{2}{*}{0.6200} \\
\hline No & $289(61)$ & $124(59)$ & $165(62)$ & \\
\hline \multicolumn{5}{|l|}{ Platelet count $\left(\times 10^{4} / \mathrm{mm}^{3}\right)$} \\
\hline Mean (SD) & $15.4(7.0)$ & $15.3(7.2)$ & $15.4(6.9)$ & 0.9642 \\
\hline \multicolumn{5}{|l|}{ ICG R15 (\%) } \\
\hline Mean (SD) & $17.0(10.3)$ & $18.0(10.5)$ & $16.3(10.1)$ & 0.0485 \\
\hline \multicolumn{5}{|l|}{ Child-Pugh classification, $\mathrm{n}(\%)$} \\
\hline A & $437(92)$ & $186(89)$ & $251(94)$ & \multirow[t]{2}{*}{0.0697} \\
\hline $\mathrm{B}$ & $40(8)$ & $23(11)$ & $17(6)$ & \\
\hline \multicolumn{5}{|l|}{$\mathrm{AFP}(\mathrm{ng} / \mathrm{ml})$} \\
\hline Median & 17.5 & 17.5 & 17.7 & \multirow[t]{2}{*}{0.9610} \\
\hline (range) & $(0.9-2873490)$ & $(1.2-167928)$ & $(0.9-2873490)$ & \\
\hline \multicolumn{5}{|l|}{ DCP (munits/l) } \\
\hline Median & 137.5 & 125.5 & 161 & \multirow[t]{2}{*}{0.6181} \\
\hline (range) & $(6-431000)$ & $(6-223000)$ & $(8-431000)$ & \\
\hline \multicolumn{5}{|l|}{ Liver histology, n (\%) } \\
\hline Normal liver + chronic hepatitis & $239(50)$ & $109(52)$ & $130(49)$ & \multirow[t]{2}{*}{0.4294} \\
\hline Liver fibrosis + liver cirrhosis & $238(50)$ & $100(48)$ & $138(51)$ & \\
\hline \multicolumn{5}{|l|}{ Tumor size $(\mathrm{cm})$} \\
\hline Mean (SD) & $4.8(3.8)$ & $5.0(3.9)$ & $4.7(3.8)$ & 0.3326 \\
\hline \multicolumn{5}{|l|}{ Number of tumors, $\mathrm{n}(\%)$} \\
\hline Solitary & $324(68)$ & $149(71)$ & $175(65)$ & 0.1630 \\
\hline Multiple & $153(32)$ & $60(29)$ & $93(35)$ & \\
\hline
\end{tabular}


Table 2 Prognostic factors for overall survival on univariate and multivariate analysis

\begin{tabular}{|c|c|c|c|c|c|}
\hline & \multicolumn{2}{|c|}{ Univariate analysis } & \multicolumn{3}{|c|}{ Multivariate analysis } \\
\hline & MST (months) & $P$ & Hazard ratio & $95 \% \mathrm{CI}$ & $P$ \\
\hline \multicolumn{6}{|l|}{ Age (years) } \\
\hline$\geq 65(\mathrm{n}=169)$ & 69.3 & 0.1541 & & & \\
\hline$<65(\mathrm{n}=308)$ & 83 & & & & \\
\hline \multicolumn{6}{|l|}{ Gender } \\
\hline Male $(\mathrm{n}=389)$ & 71.4 & 0.9746 & & & \\
\hline Female $(\mathrm{n}=88)$ & 63.4 & & & & \\
\hline \multicolumn{6}{|l|}{ Etiology of HCC } \\
\hline HBV or/and HCV (n=319) & 73.9 & 0.9248 & & & \\
\hline Others $(\mathrm{n}=158)$ & 70.4 & & & & \\
\hline \multicolumn{6}{|l|}{ The presence of previous treatment } \\
\hline \multicolumn{6}{|l|}{ for $\mathrm{HCC}$} \\
\hline Yes $(\mathrm{n}=188)$ & 62.5 & 0.2235 & & & \\
\hline No $(n=289)$ & 81.1 & & & & \\
\hline \multicolumn{6}{|l|}{ Platelet count $\left(\times 10^{4} / \mathrm{mm}^{3}\right)$} \\
\hline$<10(\mathrm{n}=101)$ & 54 & 0.0093 & 1.237 & $(0.853-1.764)$ & 0.2575 \\
\hline$\geq 10(\mathrm{n}=376)$ & 84.7 & & Reference & & \\
\hline \multicolumn{6}{|l|}{ ICG R15 (\%) } \\
\hline$\geq 15(\mathrm{n}=245)$ & 69.3 & 0.2298 & & & \\
\hline$<15(\mathrm{n}=232)$ & 97.5 & & & & \\
\hline \multicolumn{6}{|l|}{ Child-Pugh classification } \\
\hline $\mathrm{A}(\mathrm{n}=437)$ & 73.9 & 0.1120 & & & \\
\hline $\mathrm{B}(\mathrm{n}=40)$ & 45.6 & & & & \\
\hline \multicolumn{6}{|l|}{ AFP(ng/dl) } \\
\hline$\geq 20(\mathrm{n}=229)$ & 55.7 & $<0.0001$ & 1.552 & $(1.110-2.184)$ & 0.0099 \\
\hline$<20(n=248)$ & 97.5 & & Reference & & \\
\hline \multicolumn{6}{|l|}{ DCP (munits/l) } \\
\hline$\geq 40(\mathrm{n}=338)$ & 73.9 & 0.1201 & & & \\
\hline$<40(\mathrm{n}=139)$ & 71.4 & & & & \\
\hline \multicolumn{6}{|l|}{ Liver histology } \\
\hline $\begin{array}{l}\text { Normal liver or chronic hepatitis } \\
(\mathrm{n}=239)\end{array}$ & 84.7 & 0.1895 & & & \\
\hline $\begin{array}{l}\text { Liver fibrosis or liver cirrhosis } \\
(\mathrm{n}=238)\end{array}$ & 65 & & & & \\
\hline \multicolumn{6}{|l|}{ Tumor size $(\mathrm{cm})$} \\
\hline$\geq 5.0(\mathrm{n}=170)$ & 60.2 & 0.0008 & 1.248 & $(0.864-1.801)$ & 0.2374 \\
\hline$<5.0(\mathrm{n}=307)$ & 83 & & Reference & & \\
\hline
\end{tabular}


Number of tumors

Multiple $(n=153)$

62.5

0.0104

1.045

$(0.722-1.522)$

0.8155

Solitary $(n=324)$

97.5

Reference

MVI

Positive $(\mathrm{n}=152)$

41.4

$<0.0001$

1.218

(0.820-1.803)

0.3283

Negative $(n=325)$

84.7

Reference

Tumor differentiation

Well or moderate $(n=349)$

81.1

$<0.0001$

0.698

(0.490-1.003)

0.0522

Poor $(\mathrm{n}=113)$

Reference

TNM stage

I or II $(\mathrm{n}=263)$

$<0.0001$

0.477

(0.309-0.735)

0.0008

III or IV $(\mathrm{n}=214)$

45.6

Reference

Surgical procedure

$\geq$ Lobectomy $(\mathrm{n}=167)$

46.8

0.0004

1.201

(0.810-1.782)

0.3621

$<$ Segmentectomy $(\mathrm{n}=310)$

Reference

Operative time ( $\mathrm{min})$

$\geq 360(\mathrm{n}=250)$

0.0003

1.335

(0.938-1.915)

0.1090

$<360(\mathrm{n}=227)$

Operative blood loss (ml)

$\begin{array}{lcc}\geq 500(\mathrm{n}=310) & 62.5 & <0.0001 \\ <500(\mathrm{n}=167) & \cdot & \\ \operatorname{BMI}\left(\mathrm{kg} / \mathrm{m}^{2}\right) & & 0.8510 \\ \geq 25(\mathrm{n}=109) & 71.4 & \\ <25(\mathrm{n}=368) & 73.9 & \end{array}$

Preoperative IMAC

$\operatorname{High}(\mathrm{n}=209)$

$<0.0001$

2.942

(2.117-4.136)

$<0.0001$

Normal $(\mathrm{n}=268)$

Preoperative PMI
Low $(\mathrm{n}=134)$
69.3
0.3178
$\operatorname{Normal}(\mathrm{n}=343)$
77.3

$A F P, \alpha$-fetoprotein; $B M I$ body mass index, $C I$ confidence interval, $D C P$ des- $\gamma$-carboxyprothrombin, $H B V$ hepatitis $\mathrm{B}$ virus, HCC hepatocellular carcinoma, HCV hepatitis C virus, ICG R15 indocyanine green retention test at 15 min, IMAC intramuscular adipose tissue content, $M S T$ median survival time, $M V I$ microvascular invasion, $P M I$ psoas muscle mass index, TNM Tumour Node Metastasis (stage defined by the Liver Cancer Study Group of Japan). 


\begin{tabular}{|c|c|c|c|c|}
\hline Positive & $152(32)$ & $70(33)$ & $82(31)$ & 0.5010 \\
\hline Negative & $325(68)$ & $139(67)$ & $186(69)$ & \\
\hline \multicolumn{5}{|c|}{ Differentiation of HCC, $\mathrm{n}(\%)$} \\
\hline Well & $48(10)$ & $17(8)$ & $31(12)$ & \multirow[t]{4}{*}{0.5354} \\
\hline Moderate & $301(63)$ & $131(63)$ & $170(63)$ & \\
\hline Poor & $113(24)$ & $54(26)$ & $59(22)$ & \\
\hline Unknown & $15(3)$ & $7(3)$ & $8(3)$ & \\
\hline \multicolumn{5}{|l|}{ TNM stage, n (\%) } \\
\hline I & $82(17)$ & $31(15)$ & $51(19)$ & \multirow[t]{4}{*}{0.5823} \\
\hline II & $181(38)$ & $81(39)$ & $100(37)$ & \\
\hline III & $142(30)$ & $62(30)$ & $80(30)$ & \\
\hline IV & $72(15)$ & $35(17)$ & $37(14)$ & \\
\hline \multicolumn{5}{|c|}{ Surgical Procedure, n (\%) } \\
\hline$\geq$ Lobectomy & $167(35)$ & $75(36)$ & $92(34)$ & \multirow[t]{2}{*}{0.7237} \\
\hline$<$ Segmentectomy & $310(65)$ & $134(64)$ & $176(66)$ & \\
\hline \multicolumn{5}{|l|}{ Operative time (min) } \\
\hline Mean (SD) & $380(138)$ & $382(140)$ & $379(137)$ & 0.9118 \\
\hline \multicolumn{5}{|c|}{ Operative blood loss (ml) } \\
\hline Mean (SD) & $1264(2210)$ & $1399(2568)$ & $1160(1884)$ & 0.0225 \\
\hline
\end{tabular}

$A F P$ a-fetoprotein, $B M I$ body mass index, $D C P$ des- $\gamma$-carboxyprothrombin, $H B V$ hepatitis B virus, $H C C$ hepatocellular carcinoma, $H C V$ hepatitis $\mathrm{C}$ virus, ICG R15 indocyanine green retention test at $15 \mathrm{~min}, I M A C$ intramuscular adipose tissue content, $M V I$ microvascular invasion, $P M I$ psoas muscle mass index, SD standard deviation, TNM Tumour Node Metastasis (stage defined by the Liver Cancer Study Group of Japan).

Percentages might not add up to $100 \%$ because of rounding. 
Table 3 Prognostic factors for recurrence-free survival on univariate and multivariate analysis

\begin{tabular}{|c|c|c|c|c|c|}
\hline & \multicolumn{2}{|c|}{ Univariate analysis } & \multicolumn{3}{|c|}{ Multivariate analysis } \\
\hline & MST (months) & $P$ & Hazard ratio & $95 \% \mathrm{CI}$ & $P$ \\
\hline \multicolumn{6}{|l|}{ Age (years) } \\
\hline$\geq 65(\mathrm{n}=169)$ & 20.5 & 0.5766 & & & \\
\hline$<65(\mathrm{n}=308)$ & 17.7 & & & & \\
\hline \multicolumn{6}{|l|}{ Gender } \\
\hline Male $(\mathrm{n}=389)$ & 21 & 0.8394 & & & \\
\hline Female $(\mathrm{n}=88)$ & 18.2 & & & & \\
\hline \multicolumn{6}{|l|}{ Etiology of HCC } \\
\hline HBV or/and HCV (n =319) & 17.7 & 0.1694 & & & \\
\hline Others $(\mathrm{n}=158)$ & 26.3 & & & & \\
\hline \multicolumn{6}{|l|}{ The presence of previous treatment } \\
\hline \multicolumn{6}{|l|}{ for $\mathrm{HCC}$} \\
\hline Yes $(n=188)$ & 17.6 & 0.0735 & 1.254 & $(0.967-1.620)$ & 0.0879 \\
\hline No $(n=289)$ & 21.8 & & Reference & & \\
\hline \multicolumn{6}{|l|}{ Platelet count $\left(\times 10^{4} / \mathrm{mm}^{3}\right)$} \\
\hline$<10(\mathrm{n}=101)$ & 14.9 & 0.0139 & 1.201 & $(0.876-1.623)$ & 0.2504 \\
\hline$\geq 10(\mathrm{n}=376)$ & 21.5 & & Reference & & \\
\hline \multicolumn{6}{|l|}{ ICG R15 (\%) } \\
\hline$\geq 15(\mathrm{n}=245)$ & 18.9 & 0.2085 & & & \\
\hline$<15(\mathrm{n}=232)$ & 20.2 & & & & \\
\hline \multicolumn{6}{|l|}{ Child-Pugh classification } \\
\hline $\mathrm{A}(\mathrm{n}=437)$ & 19.8 & 0.6930 & & & \\
\hline $\mathrm{B}(\mathrm{n}=40)$ & 18.2 & & & & \\
\hline \multicolumn{6}{|l|}{$\mathrm{AFP}(\mathrm{ng} / \mathrm{dl})$} \\
\hline$\geq 20(\mathrm{n}=229)$ & 14.2 & 0.0043 & 1.182 & $(0.914-1.530)$ & 0.2027 \\
\hline$<20(n=248)$ & 28.1 & & Reference & & \\
\hline \multicolumn{6}{|l|}{ DCP (munits/l) } \\
\hline$\geq 40(\mathrm{n}=338)$ & 16.4 & 0.0008 & 1.343 & $(0.994-1.830)$ & 0.0550 \\
\hline$<40(\mathrm{n}=139)$ & 33.4 & & Reference & & \\
\hline \multicolumn{6}{|l|}{ Liver histology } \\
\hline $\begin{array}{l}\text { Normal liver or chronic hepatitis } \\
(\mathrm{n}=239)\end{array}$ & 24.3 & 0.0416 & 0.674 & $(0.521-0.871)$ & 0.0026 \\
\hline $\begin{array}{l}\text { Liver fibrosis or liver cirrhosis } \\
(\mathrm{n}=238)\end{array}$ & 17.7 & & Reference & & \\
\hline \multicolumn{6}{|l|}{ Tumor size $(\mathrm{cm})$} \\
\hline$\geq 5.0(\mathrm{n}=170)$ & 10.8 & 0.0023 & 1.440 & $(1.063-1.920)$ & 0.0186 \\
\hline$<5.0(\mathrm{n}=307)$ & 23.8 & & Reference & & \\
\hline
\end{tabular}


Number of tumors

Multiple $(n=153)$

Solitary $(n=324)$

11.4

26.3

1.299

$(0.955-1.757)$

0.0947

MVI

Positive $(\mathrm{n}=152)$

8.9

$<0.0001$

Reference

Negative $(n=325)$

27

1.491

$(1.082-2.042)$

0.0148

Tumor differentiation

Well or moderate $(n=349)$

0.956

$(0.712-1.297)$

0.7708

Poor $(\mathrm{n}=113)$

Reference

TNM stage

I or II $(\mathrm{n}=263)$

$<0.0001$

0.553

(0.394-0.774)

0.0006

III or IV $(\mathrm{n}=214)$

Reference

Surgical procedure

$\geq$ Lobectomy $(\mathrm{n}=167)$

0.0063

1.350

(0.986-1.855)

0.0613

$<$ Segmentectomy $(\mathrm{n}=310)$

Reference

Operative time ( $\mathrm{min})$

$\geq 360(\mathrm{n}=250)$

0.2319

$<360(\mathrm{n}=227)$

Operative blood loss (ml)

$\begin{array}{lll}\geq 500(\mathrm{n}=310) & 16.4 & 0.0066 \\ <500(\mathrm{n}=167) & 26.8 & \\ \mathrm{BMI}\left(\mathrm{kg} / \mathrm{m}^{2}\right) & & \\ \geq 25(\mathrm{n}=109) & 21.5 & 0.6060 \\ <25(\mathrm{n}=368) & 18.9 & \end{array}$

Preoperative IMAC

High ( $\mathrm{n}=209)$

Normal $(\mathrm{n}=268)$

Preoperative PMI

Low $(\mathrm{n}=134)$

$\operatorname{Normal}(\mathrm{n}=343)$
18.8

15

26.3

19.8
0.0012

1.529

(1.196-1.953)

0.0007
1.115

(0.832-1.488)

0.4647

Reference

Reference

$A F P, \alpha$-fetoprotein; $B M I$ body mass index, $C I$ confidence interval, $D C P$ des- $\gamma$-carboxyprothrombin, $H B V$ hepatitis $\mathrm{B}$ virus, HCC hepatocellular carcinoma, HCV hepatitis C virus, ICG R15 indocyanine green retention test at 15 min, IMAC intramuscular adipose tissue content, $M S T$ median survival time, $M V I$ microvascular invasion, $P M I$ psoas muscle mass index, TNM Tumour Node Metastasis (stage defined by the Liver Cancer Study Group of Japan). 